\title{
E-IMPULSE BUYING: UMA REVISÃO ACERCA DOS SEUS ANTECEDENTES, CONSEQUENTES E PROPOSIÇÃO DE FRAMEWORK INTEGRATIVO
}

\section{E-IMPULSE BUYING: A REVIEW ON ITS HISTORY, CONSEQUENTIAL AND PROPOSITION INTEGRATIVE FRAMEWORK}

\section{E-IMPULSE BUYING: UNA REVISIÓN SOBRE SUS ANTECEDENTES, CONSECUENTES Y PROPOSICIÓN DE FRAMEWORK DE INTEGRACIÓN}

\author{
Abdinardo Moreira Barreto de Oliveira \\ Professor Assistente da Universidade Federal do Vale do São Francisco (UNIVASF) \\ Doutorando em Administração pelo PROPAD/UFPE, Brasil \\ Endereço: Av. Antônio Carlos Magalhães, 510 ,Country Club , CEP: 48902-300, Juazeiro, BA - Brasil \\ Telefone: (87) 2101-6705 - E-mail: abdinardo@yahoo.com.br
}

\section{Vinícius Farias Moreira}

Professor Assistente da Universidade Federal de Campina Grande (UFCG)

Doutorando em Administração pelo PROPAD/UFPE.

Endereço: Av. Aprígio Veloso, 882, Bodocongó, CEP 58109-900, Campina Grande, PB - Brasil

Telefone: (83) 2101-1000 - E-mail: viniciusfmoreira@yahoo.com.br

\section{Salomão Alencar de Farias}

Professor Associado da Universidade Federal de Pernambuco (UFPE).

Doutorado em Administração pela Universidade de São Paulo, Brasil

Endereço: Av. Prof. Moraes Rego, 1235, Cidade Universitária, CEP 50670-901, Recife, PE- Brasil

Telefone: (81) 2126-8000 - E-mail: saf@ufpe.br

\section{Francisco Vicente Sales Melo}

Professor Assistente da Universidade Federal de Pernambuco (UFPE)

Doutorando em Administração pela Universidade Federal de Pernambuco (UFPE), Brasil

Endereço: Av. Prof. Moraes Rego, 1235, Cidade Universitária, CEP 50670-901, Recife, PE- Brasil

Telefone: (81) 2126-8000 - E-mail: vicsmelo@gmail.com

Artigo recebido em 06/04/2014. Revisado por pares em 03/08/2014. Reformulado em 03/09/2014. Recomendado para publicação em 25/11/2014 por Ademar Dutra (Editor Científico). Publicado em 30/12/2014. Avaliado pelo Sistema double blind review.
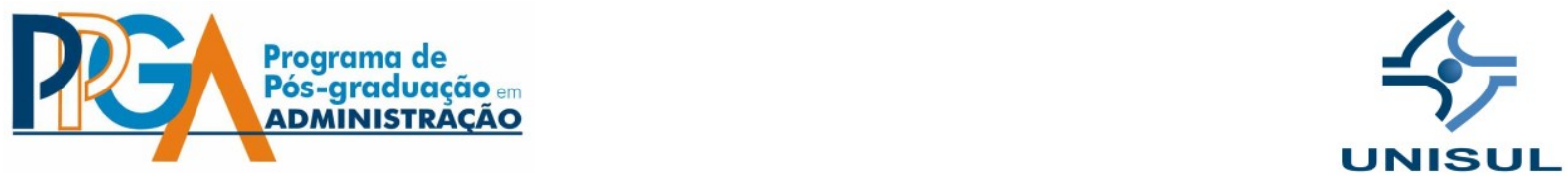

\section{(1) (9)}

EY NG ND (C) Copyright 2008 UNISUL-PPGA/Revista Eletrônica de Estratégia \& Negócios. Todos os direitos reservados. Permitida citação parcial, desde que identificada a fonte. Proibida a reprodução total. 
RESUMO

O objetivo deste trabalho é apresentar um framework integrativo sobre o e-impulse buying, dado que o conhecimento dele decorrente parece ainda estar em construção, principalmente sobre seus antecedentes e consequentes. Encontrou-se que a atmosfera da loja virtual é o principal estímulo, que sendo esta preparada para atender aos diversos comportamentos relacionados à cultura dos indivíduos (individualistas e coletivistas), gera atitudes positivas em relação à navegação no website e emoções a priori. A depender da experiência vivenciada nesse fluxo, a resposta do consumidor pode ser uma compra por impulso (com manifestação de emoções a posteriori) ou planejada.

Palavras-chave: E-impulse buying; Comércio eletrônico; Abordagem S-O-R.

\section{ABSTRACT}

The objective of this paper is presenting a framework on e-impulsing buying, considering the knowledge produced until now is not finished, we focus on the antecedents and consequences of this phenomenon. It was found that online store atmosphere is the main stimulus, prepared to attend the diverse behaviors regarding to the culture of the individuals (individualist or collectivist), and the positive emotions resulting from the store browsing are the main consequences. Depending on the experience lived in this flow; the costumer answer can be an impulse purchase (with a posteriori emotions manifested) or planned purchases.

Keywords: E-impulse buying; E-commerce; S-O-R approach.

\section{RESUMEN}

El objetivo de este trabajo es presentar un framework de integración sobre el e-impulse buying, pues el conocimiento de él decurrente aún parece estar en construcción, principalmente sobre sus antecedentes y consecuentes. Se encontró que la atmosfera de la tienda virtual es el principal estímulo, cuando preparada para atender a los diversos comportamientos relacionados con la cultura de los individuos (individualistas y colectivistas), genera actitudes positivas en relación con la navegación en el website y emociones a priori. Dependiendo de la experiencia vivenciada en ese flujo, la respuesta del consumidor puede ser una compra por impulso (con manifestación de emociones a posteriori) o planeada.

Palabras-clave: E-impulse buying; Comercio electrónico; Abordaje S-O-R. 


\section{INTRODUÇÃO}

A Internet operacionaliza um modelo de negócio que possui características únicas e diferentes de quaisquer formas de transações comerciais anteriormente conhecidas. É um ambiente virtual com hipermídias que incorporam a interatividade entre vários usuários, destacadamente entre as pessoas e com os computadores. É um eficiente canal para propaganda, publicidade e até mesmo distribuição direta de informações sobre certos bens e serviços, além de emanar a ideia de fluxo; isto é, o conceito de experiência ótima do consumidor durante a navegação no website (HOFFMAN; NOVAK, 1997).

Neste sentido, Bellman, Lohse e Johnson (1999) desenvolveram um estudo global que procurou não apenas descrever, mas também modelar o relacionamento entre as características pessoais dos usuários da Internet e suas atividades de compra, cujos resultados indicaram que o então típico comprador online tem um wired lifestyle, e uma escassa quantidade de tempo livre. A partir destes achados, os referidos autores sugeriram que os ambientes de compra online devem se utilizar de artifícios em seu design que aperfeiçoem o tempo dos usuários durante o ato de comprar.

Em estudos mais recentes, Kartavianus e Napitupulu (2012) identificaram que a facilidade no pagamento, a qualidade da informação, os benefícios da compra online e a confiança têm impacto positivo e significativo na decisão de compra do consumidor online, ratificando, por conseguinte, os resultados de pesquisas anteriores acerca destas questões. Ou seja, ao interagir com um website, o usuário está vivenciando um encontro de serviço, mesmo que de maneira eletrônica (FERNÁNDEZ-SABIOTE; ROMÁN, 2012), e do tipo selfservice (MEUTER et al., 2000), já que o primeiro relacionamento não é entre consumidores ou para com a empresa, mas com o ambiente de telepresença, o qual eles criam, interagem e experimentam (FERNÁNDEZ-SABIOTE; ROMÁN, 2012; HOFFMAN; NOVAK, 1996).

O detalhe é que certos itens desse encontro de serviço que intentam facilitar o processo de compra online dos usuários (e, por conseguinte, otimizar tempo), podem desencadear um comportamento impulsivo de compra, conforme atestam Verhagen e Van Dolen (2011), ao afirmarem que, aparentemente, cerca de $40 \%$ de todos os gastos online ocorrem por conta desse tipo de comportamento. 
Voltando-se à origem da impulsividade no consumo, Rook (1987) conceitua a compra por impulso como algo mais estreito e específico do que a compra não planejada, tratandose de uma experiência repentina e espontânea de agir acompanhado por urgência. Esse impulso é hedonicamente complexo, podendo, inclusive, estimular conflitos emocionais que conduzam à compra imediata, com o mínimo de avaliação subjetiva e revelando-se ausente de preocupação com consequências posteriores.

Além do hedonismo, Sharma, Sivakumaran e Marshall (2010) sugerem que o baixo controle cognitivo e o comportamento espontâneo nas proximidades de um objeto atraente também tendem a ativar o comportamento por impulso, e a compra pode ocorrer sem levar em conta, principalmente, os aspectos financeiros. Esses conflitos decorrentes do comportamento impulsivo situam-se entre o prazer de estar comprando aquilo que se quer e o sentimento de culpa causado pela quebra das regras orçamentárias (KIM; LAROSE, 2003).

Por outro lado, ainda que os benefícios percebidos no comércio eletrônico e o poder da impulsividade de compra estejam reconhecidos academicamente, é chamada a atenção para o fato da ocorrência de poucas pesquisas sobre a influência da loja online na compra por impulso, especialmente para quando a decisão é espontânea, dominada por emoções e imediata, ao invés de racional (VERHAGEN; VAN DOLEN, 2011). Isso faz emergir uma reflexão para os inúmeros aspectos do emergente mercado virtual, principalmente para o caso do varejo online afetar ou não as decisões de compra do consumidor, da mesma forma e intensidade que o varejo tradicional (SIQUEIRA et al., 2012).

Deste modo, é provável que haja interesse por parte de pesquisadores e profissionais do varejo em saber como a navegação na web pode estimular seus clientes a adquirirem produtos sem qualquer planejamento ou intenção de compra prévia (PARK et al., 2012).

Uma vez que os estudos acerca da compra por impulso na Internet são relativamente recentes, o objetivo deste artigo é apresentar um framework integrativo sobre as principais contribuições teóricas sobre o e-impulse buying, destacando especialmente os antecedentes e consequentes empiricamente validados e disponíveis na literatura. Para tanto, inicialmente foi realizado um desk research dos estudos relacionados, utilizando-se as técnicas de análise bibliométrica. Os artigos foram extraídos das principais bases, tais como: periódicos Capes, Spell e EBSCO. Nos tópicos seguintes serão apresentadas considerações sobre compra por impulso e suas relações com o modelo S-O-R, finalizando com a proposição do modelo e considerações finais. 


\section{COMPRA POR IMPULSO: CONCEITO, MODELO S-O-R E ANTECEDENTES}

Para se compreender os fundamentos teóricos do e-impulse buying, é importante conhecer os primeiros estudos que despertaram a atenção para a compra por impulso no varejo tradicional. Em seu artigo seminal, Rook (1987) preocupava-se em definir o que era a compra por impulso, especialmente sobre os conteúdos e as dinâmicas que o consumidor vivenciava nessa experiência, os quais, além de se saber muito pouco, inovações mercadológicas da época faziam despertar, nos clientes, o desejo de comprar impulsivamente bens e serviços mais facilmente do que anteriormente registrado. Particularmente, o autor considerava o então conceito - comportamento de compra não planejado - amplo demais para apropriadamente caracterizar o fenômeno da impulsividade nas compras.

Neste sentido, Rook (1987) conduziu um estudo exploratório e fenomenológico sobre o comportamento de compra impulsivo, cujos resultados, além de estarem consistentes com interpretações psicológicas anteriores, também serviram para estreitar o seu conceito, distinguindo-o de outras formas de compras não planejadas. Para ele, a compra impulsiva é relativamente extraordinária e excitante, frequentemente forte e urgente, além de ser uma experiência rápida, espontânea e com tendência a perturbar os hábitos corriqueiros do consumidor; é mais emocional e, por isso, é percebida por eles mais como ruim do que boa, devido à sensação de estarem fora de controle durante o ato de compra. Ademais, o autor recomendou estudos adicionais que pesquisassem os fatores situacionais que estão envolvidos na compra por impulso, destacando-se, aqui, a atmosfera da loja de varejo.

Ainda que não utilize Rook (1987) como referência, o estudo de Donovan et al. (1994) atende à recomendação supracitada e é academicamente reconhecido devido aos seguintes fatores: foi um dos primeiros a adaptar o modelo psicológico Estimulo-Organismo-Resposta (E-O-R), em inglês Stimulus-Organism-Response (S-O-R), para o estudo da atmosfera de loja, bem como na mensuração dos efeitos provocados pelo ambiente da loja no comportamento de compra dos consumidores, principalmente quanto ao tempo e ao dinheiro gastos não planejados. Em relação ao modelo S-O-R, os autores explicam que ele relaciona as características do ambiente (S) com os comportamentos de aproximação ou de afastamento 
(R) ocorridos dentro dele, mediados pelos estados emocionais do indivíduo (O) despertados pelo ambiente, ilustrados na Figura 1.

Figura 1 - Modelo S-O-R adaptado

\begin{tabular}{|c|c|c|}
\hline Estímulo ambiental (S) & $\begin{array}{l}\text { Estados Emocionais (0): } \\
\text { Prazer e excitação }\end{array}$ & $\begin{array}{l}\text { Respostas }(\mathrm{R}) \text { : } \\
\text { Aproximação ou afastamento }\end{array}$ \\
\hline
\end{tabular}

Fonte: Donovan et al. (1994, p. 284).

Neste quesito, os resultados, além de reforçarem a utilidade da adaptação do Modelo S-O-R para o estudo do comportamento dos consumidores na loja, também validaram as hipóteses de que o prazer experimentado nesse ambiente é positivamente correlacionado com o tempo e o dinheiro gastos não planejados, e que as variáveis emocionais de prazer e excitação experimentadas na loja contribuíram positivamente para o tempo extra e as compras não planejadas nela gastas, independentemente das variáveis cognitivas: qualidade percebida da mercadoria, variedade, promoções, e valor do dinheiro (DONOVAN et al.,1994).

Em termos dos antecedentes da compra por impulso, o trabalho de Beatty e Ferrel (1998) é relevante porque as pesquisas que o precederam não se concentraram em compreender plenamente este tópico; principalmente porque falharam ao modelar plenamente um conjunto de variáveis, tanto situacionais como individuais, o que resultava na baixa compreensão do processo e das diversas variáveis que afetam e são inerentes ao desencadeamento da compra por impulso.

Procurando dar continuidade aos estudos sugeridos por Rook (1987) e visando a construir um modelo multivariado válido, tendo em vista a não identificação de trabalhos anteriores que lograram tal êxito, Beatty e Ferrel (1998) identificaram os seguintes resultados:

a) Em relação à navegação dentro da loja, esta afeta positivamente as emoções positivas; em conjunto, ambas afetam a vontade de comprar impulsivamente. Por outro lado, a navegação dentro da loja é positivamente influenciada pela disponibilidade de tempo e pela tendência a comprar impulsivamente; esta última também afeta positivamente a vontade de comprar impulsivamente; 
b) Sobre as emoções positivas, elas também são positivamente influenciadas pela disponibilidade de dinheiro e pelo prazer de comprar; já as emoções negativas são negativamente afetadas pela disponibilidade de tempo e de dinheiro, mas não influenciam a vontade de comprar impulsivamente;

c) A compra por impulso é positivamente afetada, tanto pela vontade de comprar impulsivamente como pela disponibilidade de dinheiro.

Para fins de comparação, os resultados obtidos por Beatty e Ferrel (1998) podem ser reinterpretados à luz do modelo S-O-R utilizado por Donovan et al. (1994), chegando à seguinte conclusão: a navegação dentro da loja é o estímulo ambiental (S) que intenta em despertar, no consumidor, emoções positivas que culminem na vontade e, por conseguinte, a compra por impulso como resposta $(R)$, os quais são mediados pelos seguintes estados emocionais (O) do cliente: disponibilidade de tempo e de dinheiro, prazer de comprar e tendência a comprar por impulso. Por sua vez, ambos os trabalhos supracitados vão ao encontro de uma das sugestões de estudos futuros propostos por Rook (1987), os quais abriram caminhos para a compreensão dos efeitos que o ambiente (ou atmosfera) de loja pode causar no comportamento impulsivo de compra do consumidor.

Contudo, em se tratando de ambientes virtuais que visam ao comércio eletrônico via Internet, tais resultados precisavam de novas interpretações, uma vez que este novo ambiente provocou a necessidade da reconstrução da função de marketing para as novas mídias por ele trazidas (HOFFMAN; NOVAK, 1997).

\section{COMPREENSÃO DO E-IMPULSE BUYING À LUZ DO MODELO S-O-R}

Nos estudos sobre comércio eletrônico, Eroglu, Machleit e Davis (2001) apontam que o varejo online tem atraído grande atenção em função de seu potencial, com implicações para os varejistas e compradores. Para os varejistas, o comércio eletrônico representa a possibilidade de ganho de tempo na oferta dos produtos e serviços, além de representar uma grande oportunidade em face ao declínio do formato de varejo tradicional. Assim, a plataforma de serviços online permite que, por meio de melhoria da tecnologia, seja possível ofertar mais conveniência e informação sobre os produtos/serviços. Na perspectiva do 
consumidor, destacam-se a conveniência (temporal e espacial), o valor (comparando-se preço e oportunidade) e as possibilidades de consumo hedônico.

Ainda nesse mesmo pensamento, Meuter et al. (2000) falam que certas interações tradicionais no mercado físico (marketplace interactions) estão sendo substituídas por transações no mercado virtual (marketspace transactions), onde produtos e serviços existem enquanto informações digitais, e podem ser entregues através de canais baseados na informação. A Internet é o clássico exemplo de tecnologias self-service (SST em inglês), em que nenhum contato físico entre compradores e vendedores é necessário para efetuar o negócio.

Neste mesmo aspecto, Park et al. (2012) explicam que as transações comerciais que acontecem no ambiente online fazem com que vários clientes gastem mais do que o previsto (sugerindo a ocorrência de compras por impulso) devido aos seguintes aspectos: os clientes não percebem que estão gastando dinheiro, as compras são mais espontâneas do que nas lojas reais e os estímulos de marketing tornam as compras impulsivas mais fáceis por causa da diminuição da aversão ao risco dos consumidores.

De certo modo, os eventos acima descritos podem ser explicados pela experiência de fluxo. O conceito de fluxo foi desenvolvido por Csikszentmihalyi (1975), sendo definido pelo autor como a sensação holística que as pessoas sentem quando agem com total envolvimento. Na perspectiva virtual, Hoffman e Novak (1996) consideram que é o estado que ocorre durante a navegação na Web, o qual é caracterizado por uma sequência contínua de respostas facilitadas pela interação com o website. Estes são intrinsecamente agradáveis, acompanhadas de uma perda de autoconsciência [por estar inteiramente concentrado nessa interação] e com autorreforço, formalizando e ampliando, portanto, a sensação de playfulness. Uma vez ocorrida a experiência de fluxo, os autores comentam que as principais consequências para o consumidor são a melhoria no aprendizado, a melhoria nos comportamentos exploratórios e participativos, e a ocorrência de mais experiências subjetivas positivas para com o website.

Uma vez que o website é o ambiente de loja no mercado virtual do tipo SST, também é possível verificar quais são as suas influências no processo decisório dos consumidores em 
Abdinardo Moreira Barreto de Oliveira - Vinícius Farias Moreira - Salomão Alencar de Farias - Francisco Vicente Sales Melo

relação às compras por impulso. Neste sentido, o Quadro 1 apresenta as principais contribuições teóricas concebidas por autores da literatura especializada, reinterpretados através do modelo S-O-R; dado que qualquer estímulo provocado pelo ambiente da loja virtual é mediado pelos estados emocionais do indivíduo, que a depender da qualidade deste encontro de serviço, poderá desencadear uma compra planejada ou uma compra por impulso.

Quadro 1 - Contribuições teóricas sobre a compra por impulso online à luz do modelo SOR.

\begin{tabular}{|c|c|c|c|}
\hline AUTORES & ESTÍMULOS & ORGANISMOS & RESPOSTAS \\
\hline $\begin{array}{c}\text { Eroglu, Machleit } \\
\text { e Davis (2001) } \\
\text { [300 citações] }\end{array}$ & $\begin{array}{l}\text { - Atmosfera de Loja } \\
\text { Virtual: tarefas de alta } \\
\text { /baixa relevância. }\end{array}$ & $\begin{array}{l}\text { - Emoção; } \\
\text { - Cognição. }\end{array}$ & $\begin{array}{l}\text { - Comportamento de } \\
\text { aproximação/afastamento. }\end{array}$ \\
\hline $\begin{array}{l}\text { Dahlén e Lange } \\
\qquad \begin{array}{c}\text { (2002) } \\
\text { [33 citações] }\end{array}\end{array}$ & $\begin{array}{l}\text { - Ambiente de varejo; } \\
\text { - Ações de comunicação. }\end{array}$ & $\begin{array}{l}\text { - Consumidor Econômico; } \\
\text { - Consumidor Personalizado; } \\
\text { - Consumidor Ético; } \\
\text { - Consumidor Apático; } \\
\text { - Consumidor por lazer. }\end{array}$ & $\begin{array}{l}\text { - Compras planejadas; } \\
\text { - Compras não planejadas } \\
\text { (por impulso). }\end{array}$ \\
\hline $\begin{array}{c}\text { Moe (2003) } \\
{[250 \text { citações] }}\end{array}$ & $\begin{array}{l}\text { - Conteúdo das páginas } \\
\text { do site. }\end{array}$ & $\begin{array}{l}\text { - Compra dirigida; } \\
\text { - Procura e deliberação; } \\
\text { - Navegação hedônica; } \\
\text { - Construção de conhecimento. }\end{array}$ & $\begin{array}{l}\text { - Compra imediata; } \\
\text { - Compra futura; } \\
\text { - Compra planejada; } \\
\text { - Compra via estímulos. }\end{array}$ \\
\hline $\begin{array}{l}\text { Costa e Larán } \\
\qquad \begin{array}{c}\text { (2003) } \\
\text { [01 citação] }\end{array}\end{array}$ & $\begin{array}{l}\text { - Ambiente web; } \\
\text { - Circulação na loja. }\end{array}$ & $\begin{array}{l}\text { - Impulsividade do indivíduo: } \\
\text { dimensões emotiva e cognitiva. }\end{array}$ & $\begin{array}{l}\text { - Compra planejada; } \\
\text { - Compra por impulso } \\
\text { (Emoções } \\
\text { positivas/negativas a } \\
\text { posteriori). }\end{array}$ \\
\hline $\begin{array}{l}\text { Mummalaneni } \\
\text { (2005) } \\
\text { [113 citações] }\end{array}$ & - Atmosfera da webstore. & $\begin{array}{l}\text { - Prazer; } \\
\text { - Excitação. }\end{array}$ & $\begin{array}{l}\text { - Satisfação; } \\
\text { - Lealdade pretendida; } \\
\text { - Tempo gasto; } \\
\text { - Número de itens. }\end{array}$ \\
\hline $\begin{array}{l}\text { Richard (2005) } \\
\text { [93 citações] }\end{array}$ & - Atmosfera da webstore. & $\begin{array}{l}\text { - Emoção; } \\
\text { - Cognição. }\end{array}$ & $\begin{array}{l}\text { - Envolvimento nas } \\
\text { decisões de compra; } \\
\text { - Intenções de compra. }\end{array}$ \\
\hline $\begin{array}{l}\text { Manganari, } \\
\text { Siomkos e } \\
\text { Vrechopoulos } \\
\text { (2009) } \\
\text { [21 citações] }\end{array}$ & $\begin{array}{l}\text { - Layout virtual e design; } \\
\text { - Atmosfera virtual; } \\
\text { - Aspectos teatrais } \\
\text { virtuais; } \\
\text { - Presença social virtual. }\end{array}$ & $\begin{array}{l}\text { - Emoção; } \\
\text { - Cognição. }\end{array}$ & $\begin{array}{l}\text { - Comportamento de } \\
\text { aproximação/afastamento. }\end{array}$ \\
\hline $\begin{array}{l}\text { Verhagen e } \\
\text { Doven (2011) } \\
\text { [04 citações] }\end{array}$ & $\begin{array}{l}\text { - Atratividade da } \\
\text { promoção; } \\
\text { - Facilidade de uso; } \\
\text { - Comunicação do site. }\end{array}$ & $\begin{array}{l}\text { - Prazer de comprar; } \\
\text { - Tipo de navegação no site. }\end{array}$ & $\begin{array}{l}\text { - Emoções } \\
\text { positivas/negativas a priori; } \\
\text { - Vontade de comprar; } \\
\text { - Compra por impulso. } \\
\end{array}$ \\
\hline $\begin{array}{l}\text { Park et al. (2012) } \\
\text { [08 citações] }\end{array}$ & $\begin{array}{l}\text { - Variedade de seleção; } \\
\text { - Atributos de preço; } \\
\text { - Atributos sensoriais. }\end{array}$ & $\begin{array}{l}\text { - Navegação utilitarista no site; } \\
\text { - Navegação hedônica no site. }\end{array}$ & - e-impulse buying. \\
\hline
\end{tabular}

Fonte: Elaborado pelos autores.(2014).

Nota: o número de citações foi coletado no Google Scholar em 05/01/2013. 
Os estudos de Eroglu, Machleit e Davis (2001), Moe (2003) e Mummalaneni (2005) foram os mais citados conforme as análises. No entanto, é possível observar que, embora apresentem semelhança nas bases conceituais utilizadas, cada estudo apresenta uma contribuição distinta que contribuiu com o avanço do conhecimento do tema.

\subsection{ESTÍMULOS (S)}

Eroglu, Machleit e Davis (2001) conceituam estímulo como uma influência que é exercida sobre o indivíduo, afetando internamente seu estado organísmico (entendido como estado inicial ou de indiferença). Os estímulos direcionados ao comércio eletrônico são, muitas vezes, diferentes dos relacionados ao comércio tradicional, indicando a necessidade de ações de marketing específicas para impulsionar o comportamento do consumidor (DAHLÉN; LANGE, 2002).

De fato, diferentemente do comércio tradicional, no canal eletrônico algumas dimensões de estímulos não são verificadas, bem como dos apelos sensoriais (tato, olfato e paladar), sendo entendido como estímulo, nesse tipo de varejo, tudo que seja auditivo e visível aos compradores online (EROGLU; MACHLEIT; DAVIS, 2001; DAHLÉN; LANGE, 2002; PARK et al., 2012). Outro importante estímulo que deve ser ponderado está relacionado à dimensão social. Sobre este, Eroglu, Machleit e Davis (2001) alegam que embora não haja a presença física de outros compradores e vendedores no momento da compra, existem outros caminhos que não anulam esse estímulo no ambiente virtual, a exemplo dos contadores de visitas, espaço de comentários e listas de discussão.

Ademais, a flexibilidade de tempo e espaço oferecida pela plataforma online, associada às múltiplas formas de atratividade decorrentes da combinação de elementos ambientais, estruturais, sociais e estéticos, especialmente a partir do apelo visual das telas, tem impulsionado as compras por meio desse canal. Neste sentido, Eroglu, Machleit e Davis (2001) classificam as características da atmosfera da loja virtual em duas grandes categorias: tarefas de alta relevância, que incluem o conteúdo verbal relacionado aos objetivos da compra (descrição da promoção, preços, termo de venda, entrega e políticas de devolução), fotos da promoção, disponibilidade, auxílio de navegação (mapas do site e outras ferramentas de direcionamento); e tarefas de baixa relevância, que são os conteúdos verbais 
que não estão diretamente relacionados aos objetivos de compra (cores, padrões de fundo de tela, fontes e estilo da letra, animação, música e sons, entretenimento, espaços em branco, ícones, mapas de imagens, indicadores de conectividade, afiliações, etc.). A partir dessas tarefas, os autores propõem que o ambiente de loja dos compradores online consiste das informações das tarefas de alta e baixa relevância, e que estas tarefas irão influenciar o estado organísmico do comprador, podendo afetar nos resultados de compras via Web.

Essa mesma classificação é utilizada no estudo de Richard (2005), que indica a questão da atmosfera de loja virtual como crítica na efetividade do website, desde o momento em que o visitante decide por quais páginas da Web irá acessar, por quanto tempo e quanto de informação irá adquirir. Com base na literatura analisada, a autora apresenta cinco aspectos, que são classificados como tarefas de alta relevância: características de navegação, associada à facilidade de uso, presença de agentes de busca e de palavras-chaves; informatividade, indicando que o site é informativo, proveitoso e cheio de recursos; efetividade do conteúdo informado, que aponta para informação segura, atualizada e completa; estrutura do site, representando uma estrutura simples, bem organizada e com visão geral; e organização, no sentido de não ser confuso nem gerar irritação. Já quanto às tarefas de baixa relevância, a autora destacou o entretenimento, que pode ser compreendido por meio dos aspectos adicionais do site que o tornam excitante, imaginativo e divertido.

Possivelmente, estariam associadas às tarefas de alta relevância, as características de atratividade da promoção e facilidade no uso do site, aspectos relacionados à conveniência funcional apontada por Verhagen e Van Dolen (2011). Sobre a atratividade da promoção, os autores indicam que este estímulo representa a percepção de tamanho e a atratividade da variedade, o que inclui a impressão sobre o número de produtos ofertados no site, sobre as ofertas e o encaixe de tudo isso com as necessidades dos clientes, encorajando-os a navegarem e assumirem uma postura hedônica (MOE, 2003; PARK et al., 2012). Em relação à facilidade de uso do site, aspecto já destacado por autores como Eroglu, Machleit e Davis (2001) e Richard (2005), representa a possibilidade de conveniência dos clientes quando inseridos em um ambiente online. 
A atratividade pode, ainda, estar relacionada aos estímulos preço e aspectos sensoriais (PARK et al., 2012). Segundo os autores, ainda que os consumidores mais sensíveis a preço assumam comportamento de compra racional e lógico, o consumidor pode ser levado ao consumo por impulso por perceber vantagem utilitária na aquisição de bem ou serviço, constatando que o preço oportuno o convida à aquisição impulsiva. Quanto aos aspectos sensoriais, os autores comentam que os compradores procuram conhecer todas as informações sobre o produto, incluindo cor, design, tecido e caimento, estímulos que são intensificados quando se trata do público feminino.

Tais características estão associadas à circulação na loja virtual (COSTA; LARÁN, 2003). Estes autores realizaram um estudo pioneiro no Brasil sobre os antecedentes que influenciam o tipo de comportamento de compra online, propondo uma hipótese teórica associando circulação na loja online à probabilidade de compra. Embora essa relação seja observada e valiosa, não foi possível afirmar que o maior nível de circulação implicaria em maior nível de compras impulsivas junto aos consumidores online brasileiros.

Seguindo a linha de raciocínio das tarefas de alta relevância, é possível associar, também, a contribuição sobre atmosfera de loja trazida por Dahlén e Lange (2002), que destacam a importância do gerenciamento do layout da loja online. Sugerem que, nessa plataforma de serviços, é possível ter mais flexibilidade, uma vez que seja possível simular a disponibilidade de múltiplas combinações de produtos, estilos e tamanhos, além de direcionar ações promocionais específicas para o perfil do cliente virtual. Mummalaneni (2005) também comenta, em seus resultados, que quanto melhor for o design do website e sua atmosfera de loja virtual, maiores serão o prazer e a excitação experimentados pelo comprador online, variáveis estas afetivas, hedônicas e mediadoras de suas respostas.

Em uma releitura do estudo do Eroglu, Machleit e Davis (2001), que parece integrarse com o que foi apresentado nesta seção, observou-se que este se situa na proposta do framework de ambiente de loja online de Manganari, Siomkos e Vrechopoulos (2009). Nela, o ambiente de loja online é compreendido por meio de quatro dimensões: layout virtual e design do site; atmosfera virtual (cores, músicas, espaços em branco, fontes, etc.); aspectos teatrais virtuais (como técnicas de animação e interatividade); presença social virtual (Web contadores, comentários de visitantes, aglomerações). Esta proposta faz uma nova 
categorização e renomeia o modelo de Eroglu, Machleit e Davis (2001), inclusive no que diz respeito aos aspectos moderadores, em que o envolvimento passa a ser nomeado como estratégias de navegação dos consumidores (orientação para atingir metas, busca e experimental), enquanto o termo responsividade atmosférica permanece.

Os moderadores presentes no modelo de Eroglu, Machleit e Davis (2001) atuam no relacionamento entre os Estímulos e os Organismos no contexto online, correspondendo a características de personalidade do comprador. Segundo os autores, a responsividade atmosférica do website corresponde ao traço refletido na extensão em que as características ambientais influenciam as decisões dos clientes em termos de onde, como comprar e quanto tempo será dedicado às compras, enquanto que o envolvimento representa o grau de relevância pessoal, projetando as compras online em relação ao alcance dos objetivos dos compradores.

\subsection{ORGANISMOS (O)}

Organismos ou Estados Emocionais correspondem ao estado intermediário entre os estímulos e as respostas de compra e, conforme revelado pelo Quadro 1, há uma predominância de classificação em duas dimensões, a emotiva e a cognitiva. Além disso, é possível perceber as classificações quanto à orientação de compra e quanto ao tipo de navegação na plataforma online.

Sobre o estado interno emotivo e cognitivo dos compradores online, estes são considerados mediadores das relações entre o ambiente de loja online percebido e os resultados de compra (EROGLU; MACHLEIT; DAVIS, 2001; COSTA; LARÁN, 2003; RICHARD, 2005; MANGANARI; SIOMKOS; VRECHOPOULOS, 2009). O estado emotivo dos compradores pode ser classificado ao longo de muitas dimensões, entre as quais, vários trabalhos da psicologia ambiental têm destacado prazer, excitamento e predominância em direção aos estímulos ambientais. Esta última dimensão não aparece com frequência na literatura, e representa a percepção de valor em face ao serviço que Ihe é prestado. Richard (2005) destaca que a dimensão emotiva está associada às atitudes dos indivíduos no site. Já o estado cognitivo, conforme explicam Eroglu, Machleit e Davis (2001), refere-se a todas as coisas que estão na mente do consumidor, relativas à aquisição, processamento, retenção e 
recuperação da informação. O cognitivo descreve o processamento mental interno dos consumidores, incluindo atitudes, crenças, atenção, compreensão, memória e conhecimento. No contexto do varejo eletrônico, esse estado cognitivo diz respeito a como os compradores assimilam as informações que veem na tela, fazendo suas opções em decorrência dessas, o que, segundo Richard (2005), envolve o comportamento exploratório e o envolvimento com o site. Costa e Larán (2003) comentam que os estados emotivo e cognitivo interno dos compradores são dimensões que graduam a impulsividade de compra do indivíduo, cuja relação direta com a compra por impulso foi positivamente e significativamente confirmada.

Verhagen e Van Dolen (2011) destacam que, uma vez que a compra impulsiva consiste em um processo não planejado e carente de deliberação cognitiva, é durante o processo de navegação que se forma a decisão de compra. Além disso, os autores apontam as emoções como papel chave nesse processo, sendo as emoções positivas (como excitamento e entusiasmo) responsáveis pelo sentimento de gratificação instantânea por comprar o produto, aspecto que também é retratado no estudo do Mummalaneni (2005); já as emoções negativas, estas levam alguns consumidores a realizarem suas compras para descarregar os sentimentos de irritação e estresse, possibilitando que restabeleçam seu bem estar.

Park et al. (2012) indicam que a navegação no site é a chave para influenciar a compra online, esteja o consumidor navegando de forma utilitarista ou hedônica. Em estudo realizado na Coréia do Sul, os autores confirmam sua hipótese de que a navegação no site utilitarista tem um efeito negativo nas compras por impulso, enquanto que a navegação no site hedônica tem um efeito positivo nas compras por impulso. Assim, suas conclusões levam a sugerir, como estratégia de varejo de sucesso online, (1) a ênfase no valor utilitarista das seleções, incluindo novos produtos ou marcas; (2) a introdução de valores hedônicos nas promoções de vendas; e (3) a expansão das experiências sensoriais com uma atmosfera de loja virtual utilizando tecnologia avançada (como modelos virtuais 3D), de modo a conduzir os consumidores a uma compra por impulso orientada. Vale lembrar que os resultados aqui encontrados são específicos para a amostra selecionada e para vestuários; mas, ao mesmo tempo, cria novas possibilidades de investigação do tema em outros contextos. 
A literatura revisada neste trabalho permite que sejam incluídas, nesta seção, as classificações quanto à orientação de compra e quanto ao tipo de navegação na plataforma online. Assim, é destacada a classificação de Dahlén e Lange (2002) que, baseando-se em estudos prévios, aponta para cinco tipologias de orientações de compra; e o estudo de Moe (2003), que classifica o comportamento navegacional do consumidor na loja virtual em termos do padrão e do conteúdo das páginas visitadas, procurando estabelecer métricas que diferenciem os tipos de visitantes online, e que sejam capazes de predizer as chances desses visitantes serem convertidos em compradores.

A classificação de Dahlén e Lange (2002), em relação ao tipo de orientação de compra, ocorre em função das diferentes reações dos compradores ao ambiente de varejo online: (1) o consumidor econômico, racional e orientado por metas, procurando maximizar o valor do seu dinheiro; (2) o consumidor personalizado, que deseja serviços, assistência e contato pessoal; (3) o consumidor ético, que intenta em realizar compras com a sua consciência; (4) o consumidor apático, que enxerga a compra como uma tarefa necessária, porém desagradável, o qual procura realizá-la da maneira menos dolorosa possível; e (5) o consumidor por lazer, que gosta da experiência de compra e dedica muito tempo para isto.

Diferentemente da classificação anterior, a apresentada por Moe (2003) destaca o comportamento navegacional e investiga as possibilidades de que seja revertido em um processo de compra, cuja revisão de literatura aponta para quatro tipos: compra dirigida, procura e deliberação, navegação hedônica e construção do conhecimento. Uma vez empiricamente validadas, essas vêm sendo especialmente utilizadas pela academia como suporte teórico para melhor compreender a postura que o comprador online desempenha quando em contato com a webstore, sinalizando adequadamente suas respostas.

\subsection{RESPOSTAS (R)}

As respostas correspondem à etapa final do modelo S-O-R, estando associadas aos resultados de aproximação ou afastamento do comportamento do consumidor para determinado objetivo (EROGLU; MACHLEIT; DAVIS, 2001). O comportamento de aproximação refere-se às ações positivas, que podem ser direcionadas a um conjunto particular, enquanto os de afastamento correspondem ao oposto. Analisando pelo modelo e 
no contexto de compras online, os resultados decorrem dos estímulos e dos estados emocionais, junto aos aspectos moderadores. Como averiguado, o estudo de Manganari, Siomkos e Vrechopoulos (2009) segue a mesma lógica de análise desse modelo.

Para Dahlén e Lange (2002), as respostas do modelo são analisadas por meio das opções por compras planejadas ou não planejadas (entendidas aqui como compras por impulso). Os autores tentam dimensionar que os consumidores econômicos estariam menos suscetíveis à mudança de comportamento que os consumidores apáticos e os consumidores por prazer. Essa hipótese foi rejeitada em seu estudo, cabendo novas análises, vinculando o tipo de comportamento do consumidor online aos resultados da compra, seja planejada ou por impulso. Essas opções de respostas são ampliadas no trabalho de Moe (2003), que indicam que os estímulos dos conteúdos e o estilo de navegação do usuário conduzem a quatro alternativas de respostas: a compra imediata, a compra futura, a compra planejada e a compra via estímulos. As duas primeiras possuem características utilitaristas, enquanto as duas últimas possuem orientações hedônicas.

O aspecto da navegação tem relação com as respostas desencadeadas a partir do modelo de Richard (2005), que confirma que, quando os consumidores navegam na Internet, o envolvimento nas decisões de compra é positivamente relacionado com as intenções de compra. Essa autora confirma, também, que as intenções de compra correspondem ao último estágio do processo da atmosfera de $W e b$, sendo este seu principal objetivo. Complementando esse raciocínio, Park et al. (2012), a partir de estudo realizado em lojas virtuais de produtos de vestuário na Coreia do Sul, comprovam que a navegação utilitarista tem efeito negativo nas compras por impulso, enquanto a navegação hedônica tem efeito positivo.

Os modelos de Costa e Larán (2003) e de Verhagen e Van Dolen (2011) destacam, além das opções de respostas de compra por impulso e compra planejada, a questão das emoções positivas e negativas. Costa e Larán (2003) confirmaram, em seu estudo, que a ocorrência de compra por impulso influencia positivamente na formação das emoções positivas, mas rejeitaram que tal ocorrência influencie positivamente na formação das emoções negativas. 
Verhagen e Van Dolen (2011) demonstram que as emoções são cruciais para as compras impulsivas online, vendo-as como mediadoras entre as crenças nas lojas online e a compra por impulso, confirmando a aplicabilidade da Teoria Cognitiva das Emoções em situações de compra por impulso. Contudo, a diferença primordial entre os autores é que Costa e Larán (2003) pioneiramente trataram as emoções como consequentes da compra por impulso, isto é, os sentimentos que emergiram após a realização da compra; enquanto Verhagen e Van Dolen (2011) abordaram as emoções como antecedentes da compra por impulso; ou seja, os sentimentos que surgiram durante a interação no website e que culminaram na compra.

Sobre o estudo de Mummalaneni (2005), foi possível evidenciar, mesmo com as limitações de sua pesquisa que, quando suas variáveis mediadoras são estimuladas, o prazer influencia positivamente na satisfação, na lealdade pretendida e no número de itens comprados, enquanto a excitação afeta positivamente a satisfação e o tempo gasto na webstore. Em suma, o comportamento de compra do consumidor é alterado devido aos elementos presentes na atmosfera da loja virtual, que são mediados por seus estados emocionais, confirmando o uso do modelo S-O-R para o entendimento dessas relações.

Huang e Kuo (2012), admitindo o poder da impulsividade de compra no comércio eletrônico, buscaram examinar os detalhes do processo de tomada de decisão para entender de que maneira as atividades cognitivas e emocionais formam a base do comportamento de tomada de decisão. Os resultados indicaram que, em uma dessas atividades, o humor provocado aumenta o processo de impulsividade no comércio eletrônico. Isso representa uma sinalização de oportunidade para o canal Business to Consumer (B2C), de manejar o humor dos indivíduos a fim de realizarem negócios mais volumosos e rentáveis, seja através do seu próprio website ou via plataformas, como o Youtube e redes sociais. Por outro lado, não foram encontradas claras evidências para mostrar que o envolvimento pode regular os efeitos do humor eventual. O envolvimento promove um padrão de busca de informação deliberada quando o humor é suprimido, mas os efeitos não são claros quando o humor é provocado.

\section{PROPOSIÇÃO DE FRAMEWORK INTEGRATIVO}


A partir das contribuições providas pela literatura especializada em e-impulse buying à luz do modelo S-O-R, a Figura 2 apresenta um framework integrativo, o qual ilustra, de maneira sugestiva, as relações e os fenômenos ocorridos durante o processo de compra online, cujas interações são comentadas em seguida.

Conforme já discutido na seção 3.1, a atmosfera da loja virtual tem sido identificada como o principal (e talvez o único) meio para estimular as compras por impulso pela Internet. No modelo proposto, tanto as tarefas de alta e baixa relevância presentes no design e no ambiente da loja virtual [1] influenciam os estados organísmicos a priori dos compradores online (EROGLU; MACHLEIT; DAVIS, 2001; COSTA; LARÁN, 2003; RICHARD, 2005; MUMMALANENI, 2005; MANGANARI; SIOMKOS; VRECHOPOULOS, 2009; VERHAGEN; VAN DOLEN, 2011), bem como também [2] influenciam suas atitudes de navegação no website (DAHLÉN; LANGE, 2002; MOE 2003; PARK et al., 2012). Em particular, foram localizadas evidências indicando que, quando essas emoções a priori são positivas [3], elas também influenciam as atitudes de navegação no website dos consumidores (MUMMALANENI, 2005; VERHAGEN; VAN DOLEN, 2011). Também foram encontradas evidências de que as emoções a priori [6] (quando positivas) e a navegação no site [7] (quando hedônica) influenciam a urgência para comprar impulsivamente (COSTA; LARÁN, 2003; VERHAGEN; VAN DOLEN, 2011).

Figura 2 - Framework integrativo sobre e-impulse buying

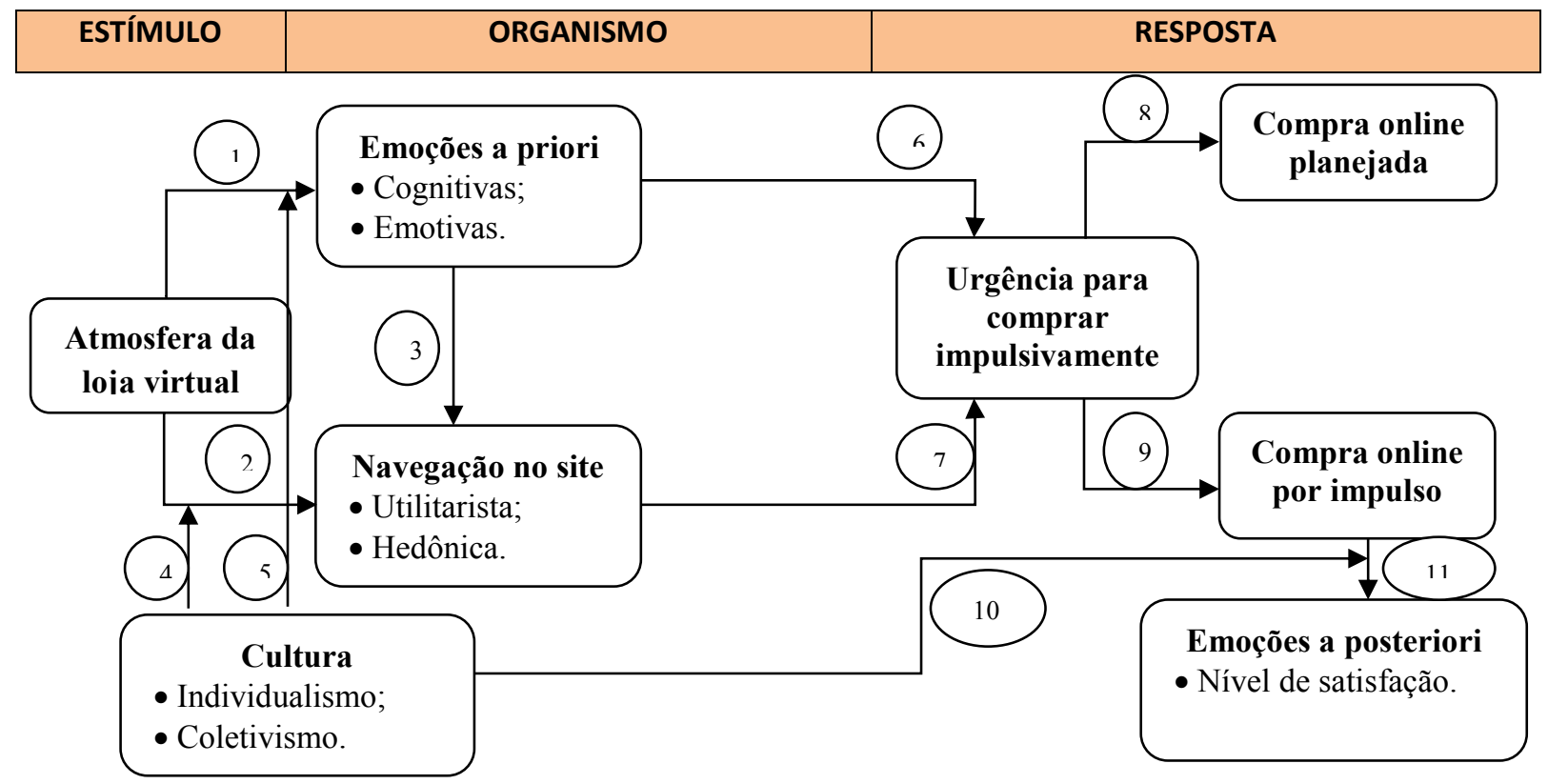


Fonte: Elaborado pelos autores. (2014).

A primeira contribuição que o framework integrativo traz para a literatura do $e$ impulse buying é a introdução da cultura como construto mediador entre os estímulos (Atmosfera de Loja Virtual) e as atitudes de navegação no website [4 em 2], e das emoções a priori [5 em 1], bem como moderador do nível de satisfação do cliente após ter sido realizado a compra por impulso [10 em 11]. A segunda contribuição é que ele lida tanto com as emoções surgidas durante a interação do cliente com o website (a priori), como com as emoções emergidas após a finalização da compra por impulso (a posteriori), mensuradas pelo seu nível satisfação com a compra.

Em seu artigo, Kacen e Lee (2002) investigaram, em lojas reais, se os fatores culturais moderavam vários aspectos no comportamento de compra por impulso dos consumidores. Tiveram, como suporte teórico, os conceitos de individualismo (padrão social que consiste de indivíduos, os quais se veem como autônom os e independentes) e de coletivismo (padrão social que consiste de indivíduos, os quais se veem como parte integrante de um ou mais grupos coletivos). Ou seja, as pessoas que vivem em culturas coletivistas frequentemente adéquam seu comportamento de compra, dependendo do contexto ou do que é correto para o grupo, enquanto as pessoas que vivem em culturas individualistas dão prioridade para suas metas pessoais, motivadas pelas suas próprias preferências, necessidades e desejos.

Kacen e Lee (2002) confirmaram que a cultura modera as características da compra por impulso. Porém, para se tornar válido, faz-se necessário avançar nos estudos considerando esta variável. Assim, necessário é imprescindível verificar se os fatores emocionais de prazer e excitação, presentes no comportamento de compra impulsiva, são mais positivamente relacionados com culturas individualistas do que com culturas coletivistas, especialmente quando o lócus de análise são os ambientes virtuais das lojas de varejo ou de serviços.

Em outro estudo, Lee e Kacen (2008) examinaram as consequências potenciais para a empresa, em termos da satisfação do consumidor, após realizarem compras por impulso, também em lojas reais. Tendo mais uma vez a cultura como plano de investigação (individualismo vs. coletivismo), elas verificaram o quanto a mera presença de outras 
pessoas pode influenciar na decisão de compra do indivíduo, que procura equilibrar suas metas individuais com as metas do grupo. Seus resultados apontaram que: (1) consumidores em culturas coletivistas estavam mais satisfeitos com a compra por impulso quando estavam com um amigo ou familiar durante a compra do que quando estavam sozinhos; (2) consumidores em culturas individualistas possuem o mesmo nível de satisfação com suas compras por impulso, independentemente de estarem acompanhados ou sozinhos; (3) quando as compras são planejadas, não existe diferença na satisfação entre individualistas ou coletivistas, estando eles acompanhados ou sozinhos.

Em conjunto, os estudos de Kacen e Lee (2002) e Lee e Kacen (2008) trazem importantes contribuições sobre a influência dos contextos culturais nas compras por impulso de seus consumidores, cujo assunto não era tratado adequadamente pela literatura corrente. Ademais, não tinham sido identificados, até o presente momento, estudos acerca do impacto da cultura no e-impulse buying, particularmente quanto à sua moderação nas emoções (a priori e a posteriori), que surgem ao longo desse processo. Nesse novo paradigma comercial, o contato com diversas culturas é inerente e inevitável, cabendo aos pesquisadores e profissionais do marketing uma melhor compreensão de sua influência nos resultados de seus negócios. Neste sentido e a partir do arcabouço teórico anteriormente citado, são apresentadas as seguintes proposições a serem verificadas nas lojas virtuais em relação ao constructo cultura:

a) $\mathrm{P}_{1}$ - Os fatores emocionais e cognitivos a priori, que caracterizam o e-impulse buying, serão mais positivamente relacionados com culturas individualistas do que com culturas coletivistas;

b) $P_{2}-A$ navegação no site do tipo hedônica será mais positivamente relacionada com culturas individualistas do que com culturas coletivistas;

c) $\mathrm{P}_{3}-$ Os consumidores em culturas coletivistas estarão mais satisfeitos com o $e$ impulse buying quando estiverem com amigos ou familiares durante a compra do que quando estiverem sozinhos;

d) $\mathrm{P}_{4}-\mathrm{Os}$ consumidores em culturas individualistas possuem o mesmo nível de satisfação com o e-impulse buying, independentemente de estarem acompanhados ou sozinhos. 
Em relação à urgência para comprar impulsivamente, estudos anteriores confirmaram que ele é um importante previsor da compra por impulso, seja em lojas reais (BEATTY; FERREL, 1998) ou em lojas virtuais (VERHAGEN; VAN DOLEN, 2011), e é para ele que os constructos precedentes do framework integrativo convergem, justamente porque é o estado de desejo que é experimentado antes da concretização da compra. Logo, quanto maior for esse sentimento, maior é a aproximação para a compra por impulso online (9); do contrário, acontecerá um afastamento do consumidor do e-impulse buying, culminando em uma compra planejada (8), ou até mesmo na realização de compra nenhuma.

\section{CONSIDERAÇÕES FINAIS}

Uma vez que as tecnologias computacionais tornaram-se parte integrante do ambiente mercadológico contemporâneo, é relevante, tanto para os acadêmicos como para os profissionais da área, entender como os consumidores agem em uma interface virtual do tipo self-service, especialmente quando a ocorrência de compras por impulso é significativa. Dado que os modelos e metodologias de análise do e-impulse buying aparentam estar ainda em formação, uma releitura a respeito do que tem sido produzido sobre a temática tornouse necessária, principalmente para observar em quais aspectos esses modelos convergiam e quais outros ainda carecem de maiores debates.

Com base nas análises, foi possível verificar que o ambiente de loja virtual pode ser o principal estímulo que o consumidor recebe quando navega no website de compra, por conta do próprio modelo de negócio. Este é moderado pela cultura (individualista e coletivista) e estimula o consumidor a ter atitudes em relação à navegação no site e emoções positivas a priori. Isso pode levar às respostas de uma compra por impulso ou uma compra planejada, mas não esquecendo de que ele poderá desistir de efetuar qualquer tipo de compra, se o encontro de serviço não lhe desencadear quaisquer experiências de fluxo para com a webstore.

Por outro lado, novas proposições são apresentadas para, por meio de estudos futuros, evidenciarem os efeitos que a cultura tem nas emoções ( $a$ priori e a posteriori) e na navegação no site no e-impulse buying, dada a ausência de estudos confirmatórios. De todo o caso, uma visão mais generalizada sobre os fenômenos que acontecem durante a compra 
por impulso online é aqui oferecida, não obstante de que o conhecimento sobre esse tema ainda continua em construção e aberto para novas interpretações, sendo esta a contribuição deste estudo. Considerando os avanços do comércio eletrônico, estudos desta natureza podem contribuir para o desenvolvimento de ações que possam envolver o consumidor no processo de compra de maneira satisfatória.

\section{REFERÊNCIAS}

BEATTY, S. E.; FERREL, M. E. Impulse buying: modeling its precursors. Journal of Retailing, v.74, n.2, p.169-191,1998.

BELLMAN, S. LOHSE, G. L.; JOHNSON, E. J. Predictors of online buying behavior. Communications of the ACM, v.42, n.12, p.32-38, dez.1999.

COSTA, F. C. X; LARÁN, J. A. A compra por impulso em ambientes on-line. Revista de Administração de Empresas, São Paulo, v.43, n.4, p.36-47, out./dez., 2003.

CSIKSZENTMIHALYI, M. Beyond boredom and anxiety: the experience of play in work and games. San Francisco: Jossey-Bass Publishers, 1975.

DAHLÉN, M.; LANGE, F. Real consumers in the virtual store. Scandinavian Journal of Management, v. 18, n. 3, p.341-363, set., 2002.

DONOVAN, R. J.; ROSSITER, J. R.; MARCOOLYN, G.; NESDALE, A. Store atmosphere and purchasing behavior. Journal of Retailing, v.70, n.3, p.283-294, 1994.

EROGLU, S. A.; MACHLEIT, K. A.; DAVIS, L. M. Atmospheric qualities of online retailing: a conceptual model and implications. Journal of Business Research, v. 54, n.2, p.177-184, nov., 2001.

FERNÁNDEZ-SABIOTE, E.; ROMÁN, S. Adding clicks to bricks: a study of the consequences on customer loyalty in a service context. Electronic Commerce Research and Applications, v.11, n.1, p.36-48, jan./fev., 2012.

HOFFMAN, D. L.; NOVAK, T. P. Marketing in Hypermedia Computer-Mediated Environments: Conceptual Foundations. The Journal of Marketing, v. 60, n. 3, p. 50-68, jul., 1996.

HOFFMAN, D. L.; NOVAK, T. P. A new marketing paradigm for electronic commerce. The Information Society, v.13, n.1, p.43-54,1997.

HUANG, Y. F.; KUO, F. Y. How impulsivity affects consumer decision-making in e-commerce. Electronic Commerce Research and Applications, v.11, n.6, p.582-590, nov./dez., 2012.

KACEN, J. J.; LEE, J. A. The influence of culture on consumer impulsive buying behavior. Journal of consumer psychology, v.12, n.2, p.163-176, 2002. 
KARTAVIANUS, O.; NAPITUPULU, T. A. Determining Factors on Purchasing Decision through E- Commerce: A Structural Equations Modelling Framework. Procedia Engineering, v.50, p.463-473, 2012.

KIM, J.; LAROSE, R. Interactive e-commerce: promoting consumer efficiency or impulsivity? Journal of computer-mediated communication, v.10, n.1, nov., 2004. Disponível em: <http://onlinelibrary.wiley.com/doi/10.1111/j.1083-6101.2004.tb00234.x/full>. Acesso em: 05 jan. 2013.

LEE, J. A.; KACEN, J. J. Cultural influences on consumer satisfaction with impulse and planned purchase decisions. Journal of Business Research, v. 61, n.3, p. 265-272, mar, 2008.

MANGANARI, E. E.; SIOMKOS, G. J.; VRECHOPOULOS, A. P. Store atmosphere in web retailing. European Journal of Marketing, v. 43, n. 9, p. 1140-1153, 2009.

MEUTER, M. L.; OSTROM, A. L.; ROUNDTREE, R. I.; BITNER, M. J. Self-service technologies: understanding customer satisfaction with technology-based service encounters. Journal of marketing, v.64, n.3, p.50-64, Jul., 2000.

MOE, W. W. Buying, Searching, or Browsing: Differentiating Between Online Shoppers Using In-Store Navigational Clickstream. Journal of Consumer Psychology, v.13, n. 1 e 2, p.29-39, 2003.

MUMMALANENI, V. An empirical investigation of Web site characteristics, consumer emotional states and on-line shopping behaviors. Journal of Business Research, v. 58, n.4, p.526- 532, abr., 2005.

PARK, E. J.; KIM, E. Y.; FUNCHES, V. M.; FOXX, W. Apparel product attributes, web browsing, and e-impulse buying on shopping websites. Journal of Business Research, v.65, n.11, p.1583-1589, nov., 2012.

RICHARD, M. O. Modeling the impact of internet atmospherics on surfer behavior. Journal of Business Research, v.58, n.12, p.1632-1642, dez., 2005.

ROOK, D. W. The Buying Impulsive. Journal of Consumer Research, v.14, p.189-199, set., 1987.

SHARMA, P.; SIVAKUMARAN, B.; MARSHALL, R. Impulse buying and variety seeking: a traitcorrelates perspective. Journal of Business Research, v.63, n.3, p. 276-283, mar., 2010.

SIQUEIRA, L. D.; CASTRO, A. D. M.; CARVALHO, J.; FARINA, M. C. A impulsividade nas compras pela Internet. Revista Eletrônica Estratégia e Negócios, Florianópolis, v.5, n.1, p.253-279, jan/abr, 2012.

VERHAGEN, T.; VAN DOLEN, W. The influence of online store beliefs on consumer online impulse buying: A model and empirical application. Information \& Management, v.48, n.8, p. 320-327, dez., 2011. 